\title{
PELATIHAN ONLINE DIGITAL IMAGING MENGGUNAKAN APLIKASI ANDROID
}

\author{
Mariza Devega ${ }^{1}$, Susi Handadayani ${ }^{2}$, Walhidayat ${ }^{3}$ \\ 1,2,3 Universitas Lancang Kuning, Pekanbaru, Indonesia \\ Jalan Yos Sudarso KM. 08 Rumbai, Pekanbaru-Riau, (0761) 53108 -53236 \\ email.marizadevega@unilak.ac.id, susi@unilak.ac.id, walhidayat@unilak.ac.id
}

\begin{abstract}
Abstrak: Banyak sector yang merasakan dampak pandemi global (covid-19) yang sudah terjadi hampir satu tahun belakangan ini. Pandemi global yang dirasakan hampir semua negara ini, mengakibatkan perekonomian menjadi lumpuh. Banyak perusahaan yang terpaksa harus gulung tikar, yang otomatis membuat semakin banyaknya pengangguran. Berdasarkan pengamatan yang dilakukan secara tentative selama masa pandemic ini, orang semakin banyak berjualan online. Berjualan secara online menjadi pilihan, karena selain tidak membutuhkan modal yang banyak, juga bisa dipasarkan seluas-luasnya. beberapa produk yang dijual baik produk jadi maupun produk olahan, sudah memiliki tampilan yang baik, karena proses pengambilan gambar dan editing dilakukan oleh tenaga professional. Namun, berbeda dengan pelaku usaha yang baru terjun dalam jual beli online yang memiliki modal seadanya tentu tidak bisa menyewa tenaga professional untuk menampilkan keindahan dan estetika dari produk yang akan dijual. Oleh karena itulah di berikan pelatihan Digital Imaging ini dilakukan untuk membantu pelaku Usaha Mikro Kecil Menengah (UMKM) dalam editing produk, sehingga produk yang dijual dapat bersaing. Editing produk yang dilakukan pun cukup mudah, hanya dengan memaksimalkan Smart Phone dengan mengunduh beberapa aplikasi yang mendukung dalam proses editing ini.
\end{abstract}

Kata kunci: Digital Imaging, produk, Penjualan Online

\begin{abstract}
Many sectors have felt the impact of the global pandemic (Covid-19) which has occurred for almost a year. The global pandemic that is being felt by almost all of these countries has caused the economy to become paralyzed. Many companies have gone out of business, which automatically creates more unemployment. Based on observations made tentatively during this time of the pandemic, more and more people are selling online. Selling online is an option, because it doesn't require a lot of capital, it can also be marketed as widely as possible. some of the products sold, both finished products and processed products, already have a good appearance, because the shooting and editing processes are carried out by professionals. However, it is different from business actors who are new to online buying and selling who have limited capital, of course they cannot hire professionals to display the beauty and aesthetics of the products to be sold. Therefore, Digital Imaging training is provided to assist Micro, Small and Medium Enterprises (MSMEs) in editing products, so that the products sold can compete. Product editing is also quite easy, just by maximizing the Smart Phone by downloading several applications that support this editing process.
\end{abstract}

Keywords: Digital Imaging, Products, Online Sales

\section{Pendahuluan}

Sudah delapan bulan terjadi pandemi global yaitu covid 19. Semua negara merasakan dampaknya, termasuk Indonesia. Dampak yang diakibatkan pandemic Covid 19 ini tidak main-main, seperti lumpuhnya perekonomian. Hal ini ditandai dengan penurunan daya beli masyarakat secara massive. Ini tentu membuat rantai supply dari hulu ke hilir tidak berjalan sebagaimana mestinya. Hampir semua sector merasakan 
dampaknya, sector industry, pendidikan, transportasi dan lain sebagainya. Tidak sedikit juga perusahaan yang harus gulung tikar, dan otomatis juga akan meningkatnya pengangguran secara besar-besaran pula.

Berdasarkan pegamatan yang dilakukan, ternyata semakin bertambah banyak orang mulai berjualan online terutama semenjak terjadinya pandemic covid 19 ini. Sebagai contoh seorang psikolog yang biasanya ada kunjungan ke sekolah-sekolah untuk mengetahui minat dan bakat siswa, harus kehilangan penghasilan selama pandemi ini karena sekolah-sekolah diliburkan. Kemudian kursus bimbingan belajar, tentu juga akan merasakan dampak serupa, selanjutnya bisnis tour dan travel, dan banyak lagi contoh lainnya yang tidak dapat disebutkan satu persatu. Oleh karena itu tidak heran bahwa, tidak sedikit dari para pekerja yang merasakan dampak langsung, akhirnya memilih berjualan secara online.

Pengamatan juga dilakukan secara tentative tentang produk yang dipasarkan secara online. Sebagian besar khususnya pelaku UMKM juga kurang update mengenai tampilan gambar, dengan kualitas gambar seadanya dan tampilan yang kurang rapi dan bagus. Oleh karena itu pelatihan Digital Imaging dianggap solusi dalam menambah kreatifitas dalam pengeditan gambar product agar terlihat lebih indah dan menarik.

Digital Imaging ini merupakan proses pengeditan atau manipulasi pada gambar (Suheryadi 2017) agar membuat tampilan gambar menjadi lebih indah. Namun disisi lain karena kemudahan untuk di rubah dan dimanupulasi, tak heran banyak disalah gunakan oleh orang yang tidak bertanggung jawab sehingga digital imaging ini sering di padukan dengan metode-metode dalam sitem keamanan, seperti steganografi yang merupakan bentuk pengamanan pesan pada sebuah media. dimana pesan disisipkan pada sebuah gambar digital (Garno and Adam 2019). Selain itu digital imaging juga dimanfaatkan sebagai analisis gambar digital dalam suatu objek yang melibatkan pixel warna serta halhal yang berhubungan dengan kualitas gambar (V.Kusumah, C.Sawung 2015).

Pada Iptek bagi Masyarakat (IbM) yang akan dilakukan , Digital Imaging yang dimaksudkan berhubungan dengan estetika pada industry komunikasi visual. Dalam proses pelatihan yang nantinya ditawarkan cukup dilakukan dengan bermodalkan android mobile phone karena lebih simple namun hasilnya cukup bagus, karena juga dilengkapi fitur-fitur yang menarik yang dapat menghubungkan pengguna ke google sehingga memudahkan pengguna dalam pencarian efek-efek gambar yang diinginkan. Sehingga diharapkan gambar produk yan hendak dijual memiliki unsur estetika dan memiliki daya saing.

\section{Metode}

Pengabdian ini dilaksanakan dengan melakukan pelatihan secara daring dengan memanfaatkan google meet. Pelatihan digital imaging itu sendiri dilakukan dengan memanfaatkan beberapa aplikasi android dalam proses editingnya. Adapun aplikasi yang digunakan yaitu: PicArts dan Vimage 
Adapun metode pelaksanaannya yaitu:

1. Tahap pertama, Pengenalan. Pada fase ini peserta pelatihan akan diberikan informasi seputar outline pembelajaran mengenai materiapa saja yang akan di bahas. kemudian tools yang nantinya akan digunakan dalam prosesnya.

2. Tahap kedua, Demonstrasi dan pelatihan. Peserta nantinya akan diberikan cara langkah-langkah kerja dari tools yang akan digunakan. Selanjutnya akan diberikan beberapa video tutorial yang akan dibagi sesuai dengan materi materi yang diberikan, agar memudahkan peserta dalam prosesnya.

3. Tahap Ketiga, Evaluasi. Proses evaluasi dilakukan dengan diberikannya waktu kepada peserta pelatihan untuk bereksplorasi sesuai dengan materi yang telah diberikan, misalnya Membuat benda seakan melayang, Membelah objek, Memadukan objek dengan back ground, Membuat efek refleksi(reflection), Berkreasi membuat foto digital imaging dengan stikers dan efect dari tools dan lain sebagainya. Selanjutnya akan diberikan kuisioner melalui dalam jaringan (daring) melalui google forms untuk mengukur pemahaman peserta dalam pelatihan yang sudah dilaksanakan.

\section{Hasil dan Pembahasan}

Pengabdian kepada masyarakat (PKM) ini dilaksanakan pada hari kamis, 3 Desember 2020 secara online dengan memanfaatkan salah satu fitur layanan gratis dari Google, yaitu Google Meet. Kegiatan dimulai pada pukul 10.00 sampai dengan pukul 11.30 WIB.

Materi diberikan dalam dua tahap, pertama, materi akan dipaparkan dan dipresentasikan secara online, dimana didalamnya berisi pengenalan tentang aplikasi yang digunakan dan tata cara pengeditan dari tiga topik editing yang dipilih dalam pengabdian masyarakat yang dilakukan ini. Kedua, diberikan video tutorial dan contoh-contoh gambar yang sudah diedit. Video tutorial ini dikirim melalui Whatsapp group yang bertujuan agar memudahkan peserta pelatihan melihat video tutorial yang diberikan secara berulang. Selain itu pembuatan group Whatsapp ini juga bertujuan sebagai wadah diskusi, Q \&A, dan sharing pemateri dan peserta maupun sesama peserta.

Setelah pemaparan dilakukan, video tutorial beserta contoh-contoh dari masingmasing topik editing diberikan, selanjutnya dilakukan survey dengan memberikan kuisioner online kepada peserta. Kuisioner yang diberikan diukur menggunakan skala Guttman. Dimana skala ini menginginkan tipe jawaban tegas. Seperti jawaban benarsalah, ya-tidak, pernah-tidak pernah, positif-negative, tinggi-rendah, baik-buruk, dan seterusnya. Skala Guttman dalam PKM ini dibuat dalam bentuk radio button dengan pilihan "ya" dan "tidak"

Berikut adalah tabel kuisioner yang diberikan kepada peserta setelah diberikannya pelatihan. Untuk jawaban positif kita beri nilai 1 dan untuk jawaban negative kita beri nilai 0 
Tabel 5.1 Kuisioner

\begin{tabular}{|l|l|l|l|l|l|l|l|l|l|l|l|}
\hline No & Responden & Q1 & Q2 & Q3 & Q4 & Q5 & Q6 & Q7 & Q8 & Q9 & Q10 \\
\hline 1. & Dewi Syafriani & 1 & 1 & 1 & 1 & 1 & 1 & 1 & 1 & 1 & 1 \\
\hline 2. & $\begin{array}{l}\text { Kathy Cooper } \\
\text { Amole }\end{array}$ & 1 & 1 & 1 & 1 & 1 & 1 & 1 & 1 & 1 & 1 \\
\hline 3. & Ferina Valentin & 1 & 1 & 1 & 1 & 1 & 0 & 0 & 0 & 0 & 0 \\
\hline 4. & $\begin{array}{l}\text { Maya Permata } \\
\text { Sari }\end{array}$ & 1 & 1 & 1 & 1 & 1 & 1 & 1 & 1 & 1 & 1 \\
\hline 5. & Irwan Siska & 1 & 1 & 1 & 1 & 1 & 1 & 1 & 1 & 1 & 1 \\
\hline 6. & Oviliza Haryuli & 1 & 0 & 0 & 1 & 1 & 1 & 1 & 1 & 1 & 1 \\
\hline 7. & Yulli Ratman & 1 & 1 & 1 & 1 & 1 & 1 & 1 & 1 & 1 & 1 \\
\hline 8. & Mariet Senja & 1 & 1 & 1 & 1 & 1 & 1 & 1 & 1 & 1 & 0 \\
\hline 9. & Eva Fitria & 1 & 0 & 0 & 1 & 1 & 1 & 1 & 1 & 1 & 0 \\
\hline 10. & Delviani & 1 & 1 & 1 & 1 & 1 & 1 & 1 & 1 & 1 & 1 \\
\hline & Total & 10 & 8 & 8 & 10 & 10 & 9 & 9 & 9 & 9 & 9 \\
\hline
\end{tabular}

Keterangan: Q1 sampai dengan Q10 adalah pertanyaan yang ada pada kuisioner

Tabel 5.2 Presentasi Pengetahuan Responden Setelah diberikan Pelatihan

\begin{tabular}{|c|c|c|}
\hline Item Pertanyaan & $\begin{array}{c}\text { Total Jawaban } \\
\text { Positif }\end{array}$ & (\%) jawaban positif \\
\hline Q1 & 10 & 100 \\
\hline Q2 & 8 & 80 \\
\hline Q3 & 8 & 80 \\
\hline Q4 & 10 & 100 \\
\hline Q5 & 10 & 100 \\
\hline Q7 & 9 & 90 \\
\hline Q8 & 9 & 90 \\
\hline Q9 & 9 & 90 \\
\hline Q10 & 9 & 90 \\
\hline Total & 9 & 90 \\
\hline Rata - rata & 91 & 910 \\
\hline
\end{tabular}

Dari table rata-rata diatas dapat dijelaskan bahwa $91 \%$ responden memberikan jawaban positif dan responsive atas pelatihan yang dilakukan.

Selanjutnya akan diperlihatkan beberapa rancangan yang dibuat oleh peserta sesuai dengan materi dalam pelatihan digital imaging yang telah diberikan: 
1. Memotong Objek dengan efek water splash
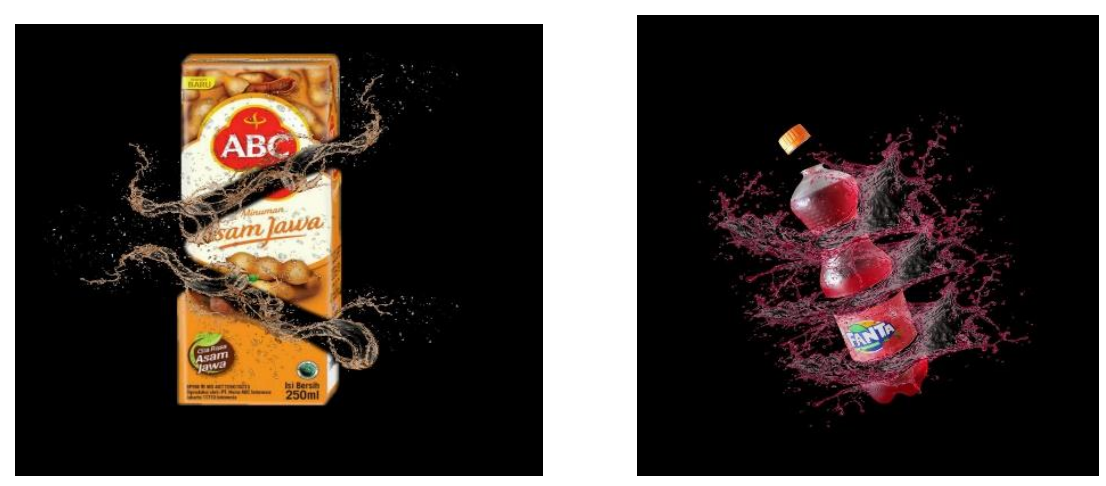

Gambar 1 Tampilan Objek yang Terpotong dengan Efek Water Splash

2. Mirror dengan efek water splash

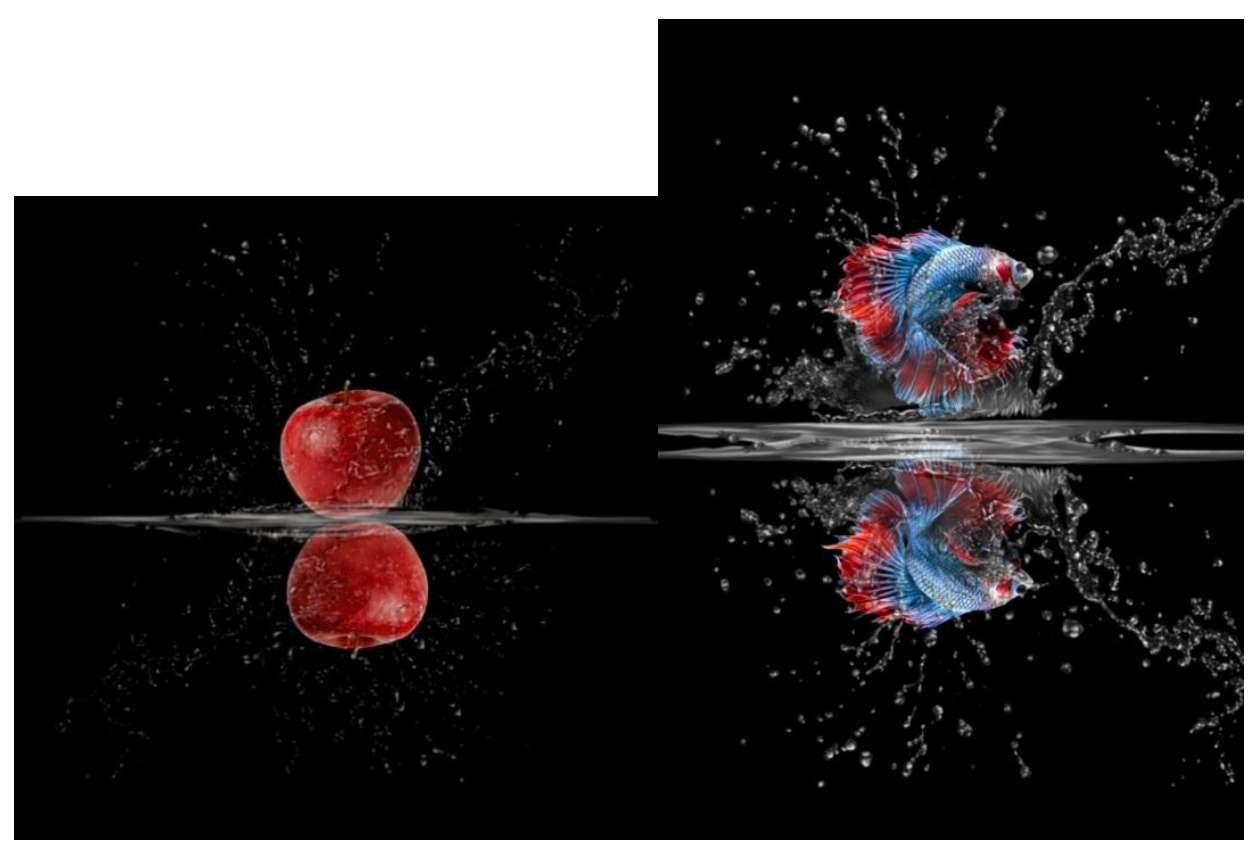

Gambar 2 Tampilan Objek dengan efek Mirror dan Water Splash

\section{Efek .gif}

Materi efek .gif ini memperlihatkan benda seolah-olah memiliki efek bergerak, contohnya memberikan efek asap yang bergerak pada makanan. Efek bergerak ini dapat terlihat jika kita mengintall aplikasi Vimage pada android. 


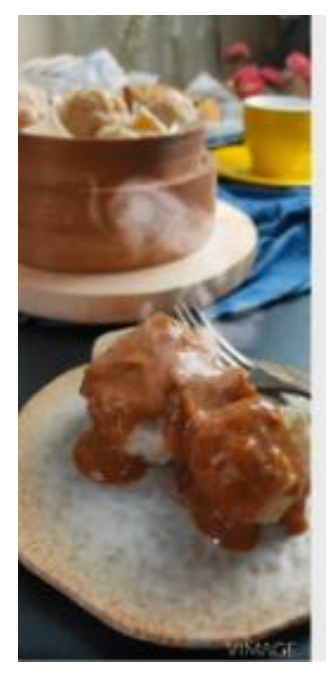

Gabar 3 Tampilan Objek dengan efek

\section{Kesimpulan}

Hasil dari evaluasi yang dilakukan berdasarkan kuisioner yang diberikan kepada peserta, dan melihat rancangan setelah diberikannya pelatihan, maka dapat disimpulkan bahwa pelatihan yang dilakukan sesuai dengan sasaran yang ingin dicapai, yaitu meningkatkan pengetahuan peserta dalam hal perancangan produk dengan memanfaatkan aplikasi android.

\section{Daftar Pustaka}

Broekhuijsen, M., van den Hoven, E., \& Markopoulos, P. (2017). From PhotoWork to PhotoUse: exploring personal digital photo activities. Behaviour and Information Technology, 36(7), 754-767. https://doi.org/10.1080/0144929X.2017.1288266

Garno, G., \& Adam, R. I. (2019). Skema Penyembunyian Data pada Gambar Berbasis Interpolasi Kubik B-Spline Menggunakan Metode Least Significant Bit (LSB). Jurnal Edukasi Dan Penelitian Informatika (JEPIN), 5(3), 255. https://doi.org/10.26418/jp.v5i3.37584

Kirk, D. S., Sellen, A. J., Rother, C., \& Wood, K. R. (2006). Understanding photowork. Conference on Human Factors in Computing Systems - Proceedings, 2, 761-770. https://doi.org/10.1145/1124772.1124885

Mills, J. S., Musto, S., Williams, L., \& Tiggemann, M. (2018). "Selfie" harm: Effects on mood and body image in young women. Body Image, 27, 86-92. https://doi.org/10.1016/j.bodyim.2018.08.007

Suheryadi, A. (2017). Penerapan Digital Watermark Sebagai Validasi Keabsahan Gambar Digital Dengan Skema Blind Watermark. JTT (Jurnal Teknologi Terapan), 3(2), 1-6. https://doi.org/10.31884/jtt.v3i2.54

V.Kusumah, C.Sawung, P. A. (2015). Budidaya Berdasarkan Analisis Gambar Digital, 10(13). 